\title{
Can CO-tolerant Anodes be Economically Viable for PEMFC Applications with Reformates?
}

\author{
J. X. Wang ${ }^{\mathrm{a}}$, P. He ${ }^{\mathrm{b}}$, Y. Zhang ${ }^{\mathrm{a}}$, and S. Ye \\ ${ }^{a}$ Department of Chemistry, Brookhaven National Laboratory, Upton, New York 11973, \\ USA \\ ${ }^{\mathrm{b}}$ Ballard Power Systems, Inc., Burnaby, British Columbia V5J 5J8, Canada.
}

Several years ago, the answer to this question was negative based on the criteria for an anode with $<0.1 \mathrm{mg} \mathrm{cm}^{-2}$ of platinum group metals to perform similarly without and with $50 \mathrm{ppm} \mathrm{CO}$ in hydrogen proton exchange membrane fuel cells (PEMFCs). Now, with the amount of $\mathrm{CO}$ impurities reduced to $10 \mathrm{ppm}$ in reformates, a $<1 \%$ performance loss with a $1.5 \%$ air-bleed has become a reasonable target. The CO-tolerant catalyst also needs to be dissolution resistant up to $0.93 \mathrm{~V}$, viz., the potential experienced at the anode during startup and shutdown of the fuel cells. We recently demonstrated our ability to simultaneously enhance activity and stability by using single crystalline Ru@Pt core-shell nanocatalysts. Here, we report that the performance target with reformates was met using bilayer-thick $\mathrm{Ru} @ \mathrm{Pt}$ core-shell nanocatalysts with $0.047 \mathrm{mg} \mathrm{cm}^{-2} \mathrm{Pt}$ and $0.024 \mathrm{mg} \mathrm{cm}^{-2} \mathrm{Ru}$ loading, supporting a positive prognosis for the economically viable use of reformates in PEMFC applications.

\section{Introduction}

Recent advances in lowering CO impurity level from $1 \%$ to $10 \mathrm{ppm}$ via preferential oxidation (PROX) of $\mathrm{CO}$ in hydrogen feeds (1) renewed interest in developing $\mathrm{CO}-$ tolerant catalysts for using reformates as an inexpensive fuel for proton exchange membrane fuel cells (PEMFCs). The savings could be considerable since the 2015 price target for hydrogen produced by reforming natural gas is $\$ 2$ per $\mathrm{kg} \mathrm{H}_{2}$, viz., $\sim 40 \%$ cheaper than pure hydrogen generated by water electrolysis that costs $\$ 3.5$ per $\mathrm{kg} \mathrm{H}_{2}(2)$.

To be economically viable, the loss in performance in a reformate-fed PEMFC must be minimal and without a much higher loading of platinum group metals. Currently, the anode Pt loading is targeted at $0.05 \mathrm{mg} \mathrm{cm}^{-2}$ for hydrogen PEMFCs (3). Adding COtolerance can justify $0.1 \mathrm{mg} \mathrm{cm}^{-2}$ for the sum of $\mathrm{Pt}$ and $\mathrm{Ru}$. Another challenge comes from the need to prevent the dissolution of $\mathrm{Ru}$ at potentials up to $0.93 \mathrm{~V}$. This is because such high potentials can occur at the anode during the startup and shutdown of fuel cells (4), and dissolved $\mathrm{Ru}$ can migrate to the cathode, so de-activating Pt catalysts for the oxygen reduction reaction $(5,6)$.

To maximize $\mathrm{Pt}$ utilization and to protect $\mathrm{Ru}$ from dissolution, we developed an economically viable method of synthesis to produce single crystalline $\mathrm{Ru}$ (core)-Pt(shell) nanoparticles with a tunable Pt shell thickness, denoted as Ru@Pt. By eliminating structural defects, we obtained sharp and ordered Ru-Pt core-shell interfaces that made 
possible for us to maximize performance and stability via fine tuning the thickness of $\mathrm{Pt}$ shells. The enhanced resistance to Ru dissolution was demonstrated earlier (7). In this study, we focus on meeting the CO-tolerance target with minimal loading of platinum group metals.

\section{Experimental}

Briefly, we used the solvent ethanol as the reductant in synthesizing carbon-supported $\mathrm{Ru}$ nanoparticles and in coating them with $\mathrm{Pt}$ atomic layers (7). We assured a narrow distribution of particle size by first reducing $\mathrm{Ru}^{3+}$ to $\mathrm{Ru}^{2+}$ in an ethanol solution of $\mathrm{RuCl}_{3}$ via heating the oil bath to $110^{\circ} \mathrm{C}$, and then assured their complete reduction by adding alkaline solution (about 3 times that of the molar amount of $\mathrm{Ru}$ ). The filtered and dried $\mathrm{Ru} / \mathrm{C}$ was annealed in hydrogen at $450{ }^{\circ} \mathrm{C}$ for $1 \mathrm{~h}$ to minimize structural defects. A coating of $\mathrm{Pt}$ was laid down in an ethanol solution of $\mathrm{H}_{2} \mathrm{PtCl}_{6}$ with the oil bath's temperature at $80^{\circ} \mathrm{C}$. If the solution was not colorless after 2 hours, a small amount of an alkaline solution was added to fully reduce the Pt precursor. In both steps, the metal yield was nearly $100 \%$ as verified by the catalyst's dry weight being consistent with the amount we calculated from the materials we used. For an average particle size about 3.5 $\mathrm{nm}$, the Pt shell thickness varies from 1 to 2 atomic layers, while the Pt:Ru atomic ratio increased from 0.5 to 1 .

Catalyst inks were made with a Nafion:carbon weight ratio of 1:1 using a mixed solvent containing water, isopropanol, and ethanol. The inks were well mixed by shaking and sonicating them before we brushed them on to the gas diffusion layers (Ballard Material Products or Sigracet GDL 25 BC). The metal loading was determined from the dry weight of coated catalysts, with the metal percentages based on the materials used in the synthesis and ink preparation.

Fuel cell performance was tested on membrane electrode assemblies (MEAs) with an active electrode area of $45 \mathrm{~cm}^{2}$. The cathode catalyst was $\mathrm{Pt} / \mathrm{C}$ ( $\mathrm{Pt}$ loading: $0.4 \mathrm{mg} \mathrm{cm}{ }^{-2}$ ), the membrane was Nafion ${ }^{\circledR} 211$, and the gas diffusion layers were obtained from Ballard Material Products. The CO stripping measurements in MEA were performed by purging the anode with $1 \% \mathrm{CO}$ balanced with $\mathrm{N}_{2}$ and then with $\mathrm{N}_{2}$ alone. The potential sweep rate was $20 \mathrm{mV} \mathrm{s}^{-1}$ and the cathode was under $\mathrm{H}_{2}$ flow.

\section{Results and Discussions}

\section{$\underline{\text { Screening Test using GDE Strips in } 1 \mathrm{M} \mathrm{HClO}_{4}} \underline{\text { Solutions }}$}

To identify the optimal Ru:Pt atomic ratio and the ratio of total metal weight to carbon support, we conducted screening tests using gas diffusion electrodes (GDEs) in solution electrochemical cells with a $\mathrm{Pt}$ counter electrode and an $\mathrm{Ag} / \mathrm{AgCl}$ reference electrode. The rate of gas flow was kept constant and a three-way valve was used to switch between hydrogen without and with $270 \mathrm{ppm}$ CO. Figure 1 a-c present the results for six GDE samples; Table I summarizes their components and the performance parameters. We used a consistent color code in the three plots and in the Table. 


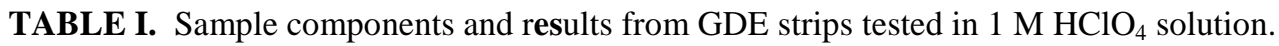

\begin{tabular}{|c|c|c|c|c|c|c|}
\hline Sample label & 1 & 2 & 3 & 4 & 5 & 6 \\
\hline Ru:Pt atomic ratio & 0 & 0.75 & 1 & 1 & 1 & 2 \\
\hline Total metal weight \% & 45 & 52 & 47 & 47 & 37 & 29 \\
\hline $\operatorname{Pt}\left(\mu \mathrm{g} \mathrm{cm}^{-2}\right)$ & 67 & 56 & 55 & 23 & 24 & 20 \\
\hline $\mathrm{Ru}\left(\mu \mathrm{g} \mathrm{cm}^{-2}\right)$ & 0 & 22 & 28 & 12 & 12 & 21 \\
\hline$C\left(\mu \mathrm{g} \mathrm{cm}^{-2}\right)$ & 82 & 72 & 94 & 39 & 62 & 103 \\
\hline Estimated $\mathrm{A}_{\mathrm{Pt}} / \mathrm{A}_{\text {Electrode }}$ & 37 & 49 & 55 & 23 & 24 & 40 \\
\hline CTR $\left(\Omega \mathrm{cm}^{2}\right)$ with $\mathrm{H}_{2}$ and $270 \mathrm{ppm}$ CO & 0.78 & 0.56 & 0.28 & 0.35 & 0.52 & 1.0 \\
\hline \% loss in current with 270 ppm CO & 41 & 39 & 36 & 36 & 49 & 46 \\
\hline \% loss in current after switch back to $\mathrm{H}_{2}$ & 16 & 4 & 1 & 2 & 8 & 11 \\
\hline
\end{tabular}
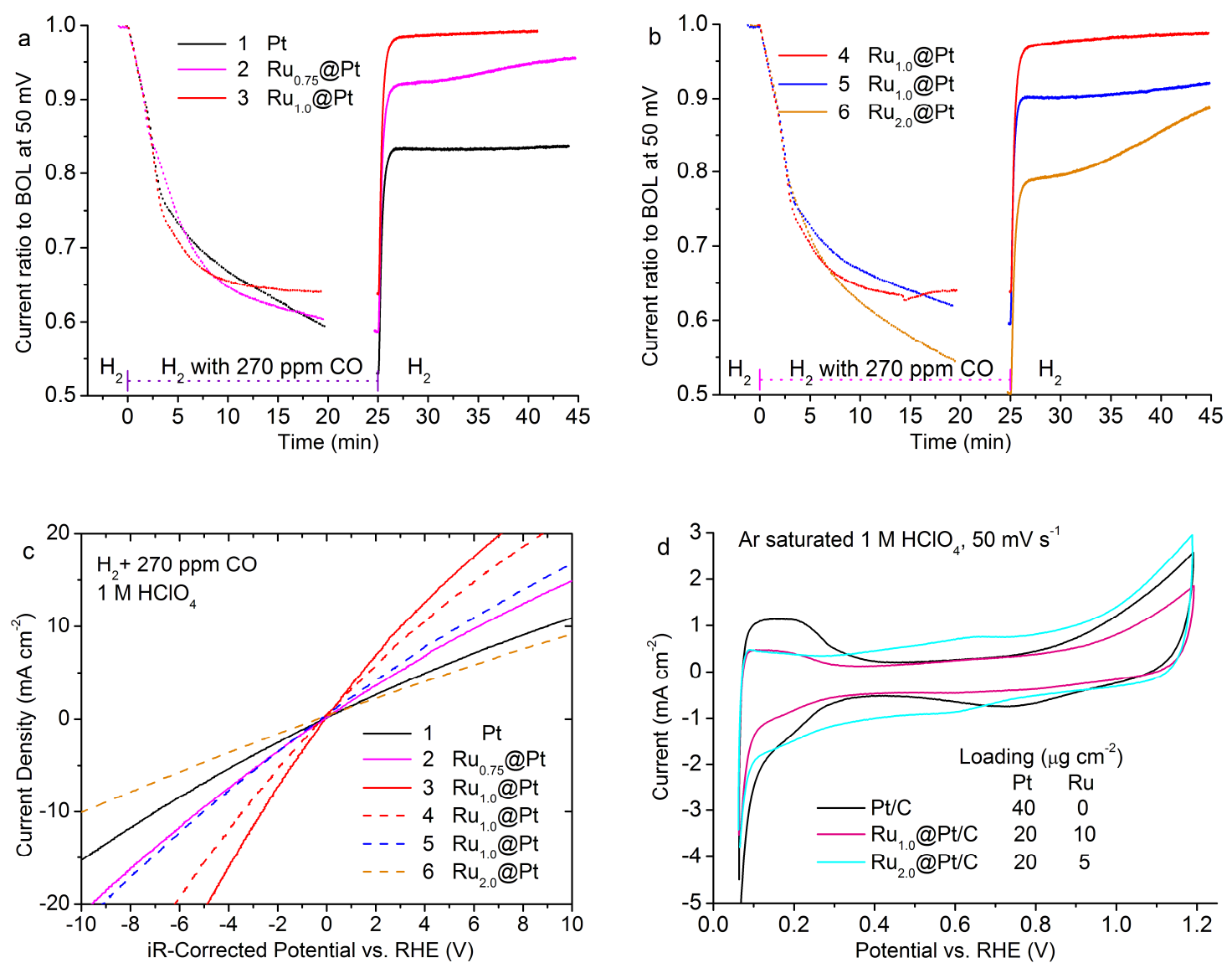

Figure 1. Performance for hydrogen oxidation reaction measured on six GDE samples in a $1 \mathrm{M} \mathrm{HClO}_{4}$ solution at $23{ }^{\circ} \mathrm{C}$. (a,b) The change of currents at $50 \mathrm{mV}$ relative to that at the beginning of the life (BOL) in $\mathrm{H}_{2}$ as a function of time with the gas inlet switched at 0 and 25 min. (c) iR-corrected polarization curves measured after 20 min with 270 ppm CO in $\mathrm{H}_{2}$. (d) Typical voltammetry curves for $\mathrm{Pt} / \mathrm{C}$, bilayer $\mathrm{Ru} @ \mathrm{Pt} / \mathrm{C}$, and monolayer $\mathrm{Ru}_{2} @ \mathrm{Pt} / \mathrm{C}$ catalysts measured in Ar-saturated $1 \mathrm{M} \mathrm{HClO}_{4}$ solution.

We labeled the samples in sequence with increasing Ru:Pt atomic ratio (second row), and then with decreasing total metal weight percentage (third row). Samples \#3 and \#4 were made with the same catalysts, differing only in loading. One is in the relatively high loading group of samples \#1-3, and another in the lower loading group of samples \#4-6. 
The loadings were determined from measured weights and thus slightly differ within the group. Table I gives the ratios of Pt surface area $\left(A_{P t}\right)$ to electrode surface area $\left(A_{\text {electrode }}\right)$ that were estimated based on a Pt specific surface area of $1.0 \mathrm{~cm}^{2} \mu \mathrm{g}^{-1}$ for the $1: 1 \mathrm{Ru}: \mathrm{Pt}$ atomic ratio bilayer catalyst determined using the $\mathrm{CO}$ striping charge, and that of 0.56 $\mathrm{cm}^{2} \mu \mathrm{g}^{-1}$ for the Pt/C determined by the hydrogen adsorption charge.

We show in Figures $1 \mathrm{a}$ and $1 \mathrm{~b}$ the changes in the hydrogen oxidation reaction (HOR) currents at $50 \mathrm{mV}$ upon switching to $\mathrm{CO}$-containing hydrogen at 0 min and switching back to pure hydrogen at $25 \mathrm{~min}$. There is a 5 minute gap between the two parts of curves because we measured polarization curves and high frequency resistances during that time; they yielded the iR-corrected polarization curves shown in Figure 1c. From the slopes obtained by linear fitting near $0 \mathrm{~V}$, we determined the values of the charge transfer resistances (CTRs) that we list in Table I to quantify the activity on an absolute scale. We note that the activity is proportional to 1 / CTR, i.e., a lower CTR represents a higher activity. In relative terms, the losses in performance due to $\mathrm{CO}$ adsorption are expressed in percentages for the currents at $50 \mathrm{mV}$ measured $20 \mathrm{~min}$ after introducing COcontaining hydrogen, and then after 20 min recovery in pure hydrogen, both with respect to that at the beginning of the life (BOL) in hydrogen (the last two rows in Table I).

The lowest CTR and percentage losses indicate the best performance; they were obtained with the catalyst having 1:1 Ru:Pt ratio and 47\% metal weight (\#3 and \#4). Without the Ru core (\#1), the HOR current had not stabilized after 20 min in the presence of $\mathrm{CO}$, and then recovered poorly after switching back to pure hydrogen (Figure 1a). The sample made with 3:4 Ru:Pt atomic ratio (\#2) exhibited a behavior in between those of $\# 1$ and \#3, indicating that going beyond the thickness of a bilayer shell made the surface property too close to that of pure Pt nanoparticles (\#1). For the low loading group (Figure $1 b$ ), increasing the metal weight percentage from $37 \%$ (\#5) as in our previous studies to $47 \%$ (\#4) in this work had a positive effect, probably due to a more compact catalyst layer. The monolayer catalyst with Ru:Pt atomic ratio of 2:1 performed poorly, consistent with the trend we found previously (7).

The change of surface properties with the thickness of Pt shell can be seen in voltammetry curves in Figure 1d. While the hydrogen adsorption current is hard to see on the monolayer $\mathrm{Ru}_{2} @ \mathrm{Pt} / \mathrm{C}$ (light blue), the curve for the bilayer Ru@Pt/C (pink) exhibits features analogous to that of $\mathrm{Pt} / \mathrm{C}$, i.e., having a clear double layer region between hydrogen adsorption at low potentials and $\mathrm{OH} / \mathrm{O}$ adsorption at high potentials. Since the $\mathrm{Pt}$ specific surface area for the bilayer Ru@ Pt/C is approximately twice that of Pt/C (1.0 versus $\left.0.56 \mathrm{~cm}^{2} \mu \mathrm{g}^{-1}\right)$, while the Pt loading is half $\left(20\right.$ versus $40 \mu \mathrm{g} \mathrm{cm}^{-2}$ ), the two electrodes have about the same $\mathrm{Pt}$ surface area. Thus, the lower $\mathrm{H}$ and $\mathrm{OH} / \mathrm{O}$ adsorption currents on the bilayer Ru@Pt/C support that the Pt surface becomes less reactive by interacting with a Ru core. Fortunately, the HOR activity is not affected by weakened hydrogen adsorption, while dissolution resistance is enhanced by weakened $\mathrm{O} / \mathrm{OH}$ adsorption. In contrast, the high oxidative current at high potentials on the monolayer $\mathrm{Ru}_{2} @ \mathrm{Pt} / \mathrm{C}$ suggests that a $\mathrm{Pt}$ monolayer cannot prevent $\mathrm{Ru}$ dissolution. This is an additional reason for why the bilayer Ru@Pt/C is the most promising HOR catalysts for PEMFCs. For conventional PtRu/C, Ru even is present in the top surface layer, and thus, dissolution of $\mathrm{Ru}$ is a serious problem. 


\section{$\underline{\text { MEA Test with Reformates }}$}

We prepared an anode GDE with bilayer Ru@Pt/C at 47\% metal weight percentage and tested its performance in PEMFC with a reformate comprising $72 \% \mathrm{H}_{2}, 20 \% \mathrm{CO}_{2}$, $8 \% \mathrm{~N}_{2}$, and $10 \mathrm{ppm} \mathrm{CO}$ with $1.5 \%$ air bleed and compared it to that with pure hydrogen using Ballard Power Systems' standard protocols. Figure 2 shows that the two polarization curves differ only slightly, and their difference can be fully described by a constant factor in currents, as is evidenced by a curve generated by dividing the currents of the reformate polarization curve (red pluses) by 0.8 (red crosses) that matches the hydrogen polarization curve (blue circles) very well. This fact favors the absence of losing active surface sites due to $\mathrm{CO}$ adsorption because otherwise the loss would have become bigger at higher currents, as usually seen. Combining this nearly perfect match over the entire curve with the dilution correcting factor not exceeding $1 / 0.72$ for the $72 \%$ $\mathrm{H}_{2}$ in the reformate, we concluded that the anode performance had no loss due to $\mathrm{CO}$, and thus, met the target of a $<1 \% \mathrm{CO}$-induced performance loss using a reformate containing 10 ppm CO with $1.5 \%$ air bleed. This result is significant because the loading of 0.047 $\mathrm{mg} \mathrm{cm} \mathrm{cm}^{-2} \mathrm{Pt}$ and $0.024 \mathrm{mg} \mathrm{cm}^{-2} \mathrm{Ru}$ are respectively $50 \%$ and $75 \%$ lower than the loading needed using conventional PtRu/C catalysts (i.e., $0.1 \mathrm{mg} \mathrm{cm}^{-2} \mathrm{Pt}$ and $0.1 \mathrm{mg} \mathrm{cm}^{-2} \mathrm{Ru}$ ); Furthermore, the Pt loading is no more than the target for using conventional $\mathrm{Pt} / \mathrm{C}$ with pure hydrogen.

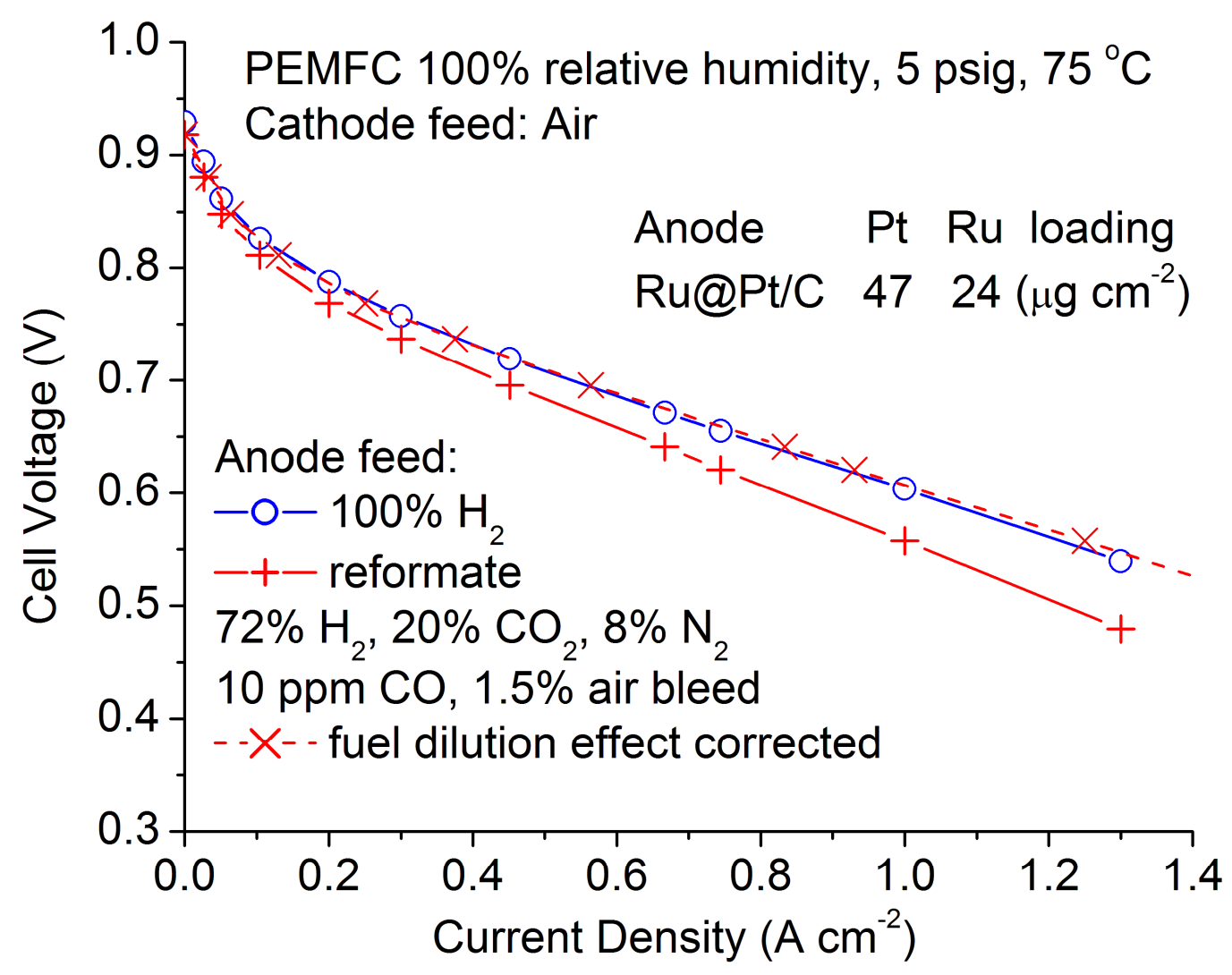

Figure 2. PEMFC polarization curves obtained using an anode comprising bilayer $\mathrm{Ru} @ \mathrm{Pt} / \mathrm{C}$ catalysts with pure hydrogen (blue circles) and reformate (red pluses) as the fuel. The curve with red crosses is generated by a correcting factor of $1 / 0.8$ to account for the effects of diluting the fuel. 
To characterize the catalysts, we carried out $\mathrm{CO}$ stripping measurements in MEA after saturating $\mathrm{CO}$ adsorption on the catalysts' with $1 \% \mathrm{CO}$ in $\mathrm{N}_{2}$. The surface area ratio $\mathrm{A}_{\mathrm{Pt}} / \mathrm{A}_{\text {electrode }}$ was estimated from the measured $\mathrm{CO}$ stripping charge (solid blue line in Figure 3) using the commonly assumed value of $0.42 \mathrm{mF} \mathrm{cm}^{-2}$, i.e., twice of the $0.21 \mathrm{mF}$ $\mathrm{cm}^{-2}$ hydrogen adsorption charge (8). The value of 48 with a loading of $47 \mu \mathrm{g} \mathrm{cm}^{-2}$ yields a Pt specific area of $48 / 47=1 \mathrm{~cm}^{2} \mu \mathrm{g}^{-1}$ or $100 \mathrm{~m}^{2} \mathrm{~g}^{-1}$ for the bilayer $\mathrm{Ru} @ \mathrm{Pt} / \mathrm{C}$ catalyst.

Figure 3 also shows that the potential of CO-stripping peak for the bilayer Ru@Pt/C is lower than that for $\mathrm{Pt} / \mathrm{C}$ and higher than that for a conventional $\mathrm{PtRu} / \mathrm{C}$. Because the atomic mass ratio for $\mathrm{Ru}: \mathrm{Pt}$ is $101 / 195=0.52$, the alloy $\mathrm{PtRu} / \mathrm{C}$ with equal weights of $\mathrm{Pt}$ and $\mathrm{Ru}$ corresponds to roughly a $\mathrm{Ru}: \mathrm{Pt}$ atomic ratio of 2 . Thus, the $\mathrm{Ru}$ contents in the alloy $\mathrm{PtRu} / \mathrm{C}$ is higher than the 1:1 atomic ratio, bilayer $\mathrm{Ru} @ \mathrm{Pt} / \mathrm{C}$. Besides, having both $\mathrm{Ru}$ and $\mathrm{Pt}$ at the surface is known to down shift the $\mathrm{CO}$ stripping peak potential (9). The effect supports a bifunctional mechanism, wherein $\mathrm{Ru}$ sites induce $\mathrm{O} / \mathrm{OH}$ adsorption at low potentials to facilitate oxidative removal of adsorbed $\mathrm{CO}$ molecules at nearby Pt sites. While this mechanism is important for oxidation of methanol and formic acid $(10,11)$, it is not necessarily so for the HOR with reformates because CO stripping anyway occurs at potential far higher than the anode's operating potential of $<0.1 \mathrm{~V}$ for hydrogen PEMFCs. Therefore, we chose to measure the response of the HOR current to the presence of $\mathrm{CO}$ at $0.05 \mathrm{~V}$ in our screening tests (Table I and Figure 1).

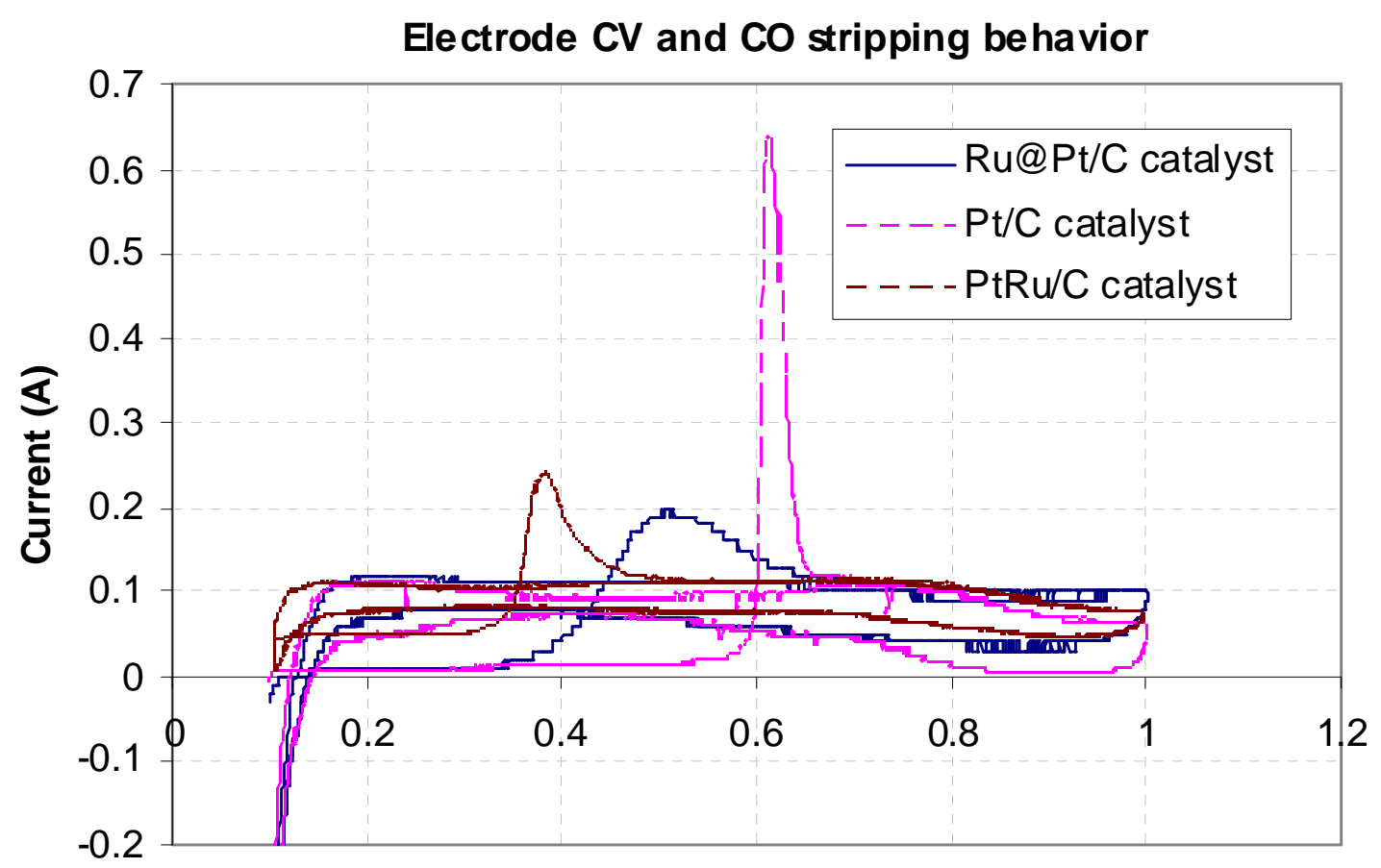

Electrode potential ( $\mathrm{V}$ vs. $\mathrm{H}_{2}$ electrode in an MEA)

Figure 3. Anode's CO stripping behavior of the bilayer Ru@ Pt/C (solid blue line) in comparison with those of conventional $\mathrm{Pt} / \mathrm{C}$ (pink dashed line) and $\mathrm{PtRu} / \mathrm{C}$ (brown dashed line) catalysts. The metal loading for the bilayer Ru@Pt/C electrode is $47 \mu \mathrm{g} \mathrm{cm}^{-2}$ Pt and $24 \mu \mathrm{g} \mathrm{cm}^{-2} \mathrm{Ru}$. 


\section{Conclusions}

A CO-tolerant anode was made using the best performing bilayer $\mathrm{Ru} @ \mathrm{Pt} / \mathrm{C}$ catalysts selected by screening test in $1 \mathrm{M} \mathrm{HClO}_{4}$ solutions. With only $47 \mu \mathrm{g} \mathrm{cm}{ }^{-2} \mathrm{Pt}$ and $24 \mu \mathrm{g}$ $\mathrm{cm}^{-2} \mathrm{Ru}$ metal loadings, the loss in currents with a reformate comprising $72 \% \mathrm{H}_{2}, 20 \%$ $\mathrm{CO}_{2}, 8 \% \mathrm{~N}_{2}$, and $10 \mathrm{ppm} \mathrm{CO}$ with $1.5 \%$ air bleed was found only $20 \%$ over entire voltage region, that can be fully accounted for by the effect of fuel dilution, with no loss in active sites due to $\mathrm{CO}$ adsorption.

This unprecedented performance is achieved by having an atomically sharp, ordered core-shell interface. For operating with reformate in PEMFCs, bilayer is the optimal thickness of Pt shell - providing just right amount electronic influence from a Ru core in optimizing Pt's surface properties, and, at the same, encapsulating Ru with a complete Pt shell to enhance $\mathrm{Ru}$ dissolution resistance.

\section{Acknowledgments}

Part of this material is based upon work supported by the U.S. Department of Energy Office of Science, Office of Basic Energy Sciences under Award Number DE-AC02-98CH10886.

\section{References}

1. K. Liu, A. Wang, T. Zhang, ACS Catalysis 2012, 2, 1165-1178.

2. Satyapal, S. Fuel Cell Technologies Update, p. 17 in Hydrogen and Fuel Cell Technical Advisory Committee Meeting, Washington, DC (2013). http://www.hydrogen.energy.gov/pdfs/htac_apr13_1_satyapal.pdf.

3. K. C. Neyerlin, W. B. Gu, J. Jorne and H. A. Gasteiger, Journal of the Electrochemical Society, 154, B631 (2007).

4. P. He, T. T. H. Cheng, R. Bashyam, Y. A. P. and K. S., ECS Trans., 33(1), 1273 (2010).

5. T. T. H. Cheng, N. Y. Jia and P. He, Journal of the Electrochemical Society, 157, B714 (2010).

6. E. Antolini, Journal of Solid State Electrochemistry, 15, 455 (2011).

7. Y. C. Hsieh, Y. Zhang, D. Su, V. Volkov, R. Si, L. J. Wu, Y. M. Zhu, W. An, P. Liu, P. He, S. Y. Ye, R. R. Adzic and J. X. Wang, Nature Communications, 4, 2466 (2013).

8. M. Bernechea, S. Garcia-Rodriguez, P. Terreros, E. de Jesus, J. L. G. Fierro and S. Rojas, Journal of Physical Chemistry C, 115, 1287 (2011).

9. H. A. Gasteiger, N. Markovic, P. N. Ross and E. J. Cairns, Journal of Physical Chemistry, 98, 617 (1994).

10. H. A. Gasteiger, N. Markovic, P. N. Ross and E. J. Cairns, Electrochimica Acta, 39, 1825 (1994).

11. N. Muthuswamy, J. L. G. de la Fuente, D. T. Tran, J. Walmsley, M. Tsypkin, S. Raaen, S. Sunde, M. Ronning and D. Chen, International Journal of Hydrogen Energy, 38, 16631 (2013). 